\title{
Sobre a definição terminológica
}

\section{On terminological definitions}

\author{
Bruna Elisa da Costa Moreira ${ }^{1}$ \\ Universidade de Brasília (UnB), Brasília / Brasil \\ brunamoreira@aluno.unb.br
}

Resumo: O presente artigo aborda aspectos que concernem à prática lexicográfica e terminográfica; particularmente, a questão da definição. O objetivo é prover um modelo satisfatório de definição terminológica e, para tanto, este estudo pretende investigar, na prática, como se elabora uma definição lexicográfica, de modo a consubstanciar tal modelo. De caráter descritivo e analítico, o trabalho é baseado em revisão de literatura, bem como na análise de definições de cinco obras - (i) Oxford English dictionary (ii) Cambridge dictionary; (iii) Dicionário de usos do português do Brasil; (iv) Dicionário Houaiss da língua portuguesa; e (v) Wordnik online dictionary. $\mathrm{O}$ artigo orienta-se pelos procedimentos metodológicos do "Roteiro para avaliação de dicionários e glossários científicos e técnicos", de Faulstich (2011), e apresenta como resultado um modelo simples e conciso de definição terminológica, concluindo com alguns exemplos da aplicação desse modelo.

Palavras-chave: terminologia; lexicografia; definição; dicionário.

Abstract: This paper focuses on aspects concerning lexicographical and terminological practices, in particular the issue of definition. Its main objective is to provide a satisfactory model for the terminological

\footnotetext{
${ }^{1}$ Pesquisadora junto ao Programa de Pós-Graduação em Linguística da Universidade de Brasília - UnB, bolsista Capes do Programa Nacional de Pós-Doutorado (PNPD/ CAPES).
} 
definition. Thusly, it investigates the elaboration of lexicographic definitions, in order to substantiate such model. This work is descriptive in nature and it is based on literature review and analysis of lexicographic definitions from five different sources - (i) Oxford English dictionary; (ii) Cambridge dictionary; (iii) Dicionário de usos do português do Brasil; (iv) Dicionário Houaiss da língua portuguesa; and (v) Wordnik online dictionary. The paper follows the methodological procedures for the "evaluation of scientific and technical dictionaries and glossaries", proposed by Faulstich (2011), and reports as result a simple and concise model of terminological definition. This paper concludes with some examples of the application of the aforementioned model.

Keywords: terminology; lexicography; definition; dictionary.

Recebido em: 11 de abril de 2016.

Aprovado em: 30 de agosto de 2016.

\section{Introdução}

A lexicografia ocupa-se da elaboração de dicionários, assim como a terminologia ocupa-se da elaboração de dicionários ou repertórios terminológicos. ${ }^{2}$ Segundo Cabré (1993), esse é um dos pontos em que se aproximam as duas disciplinas. Entretanto, "lexicografia e terminologia se diferenciam por outros aspectos, que fazem do dicionário de língua comum um produto diferente de uma obra de terminologia especializada" (CABRÉ, 1993, p. 90). Com relação aos aspectos que aproximam essas duas disciplinas, este artigo aborda especificamente o papel da definição. ${ }^{3}$ De um ponto de vista prático e descritivo, a definição de um vocábulo é, informalmente, o texto que o consulente encontra ao folhear um dicionário (ou outro repertório lexicográfico) em busca do significado de uma expressão. ${ }^{4}$ A definição lexicográfica é aquela

\footnotetext{
${ }^{2}$ Entende-se por 'terminologia' a disciplina concebida por Wüster, em 1974, como "uma zona fronteiriça entre a linguística, a lógica, a ontologia e as ciências especializadas" (WÜSTER, 1996, p. 153).

${ }^{3}$ Este artigo é parcialmente baseado em Costa (2008).

${ }^{4}$ Para uma boa introdução sobre a diferença entre dicionário, glossário e vocabulário, ver o trabalho de Vilarinho (2013, p. 51).
} 
que serve ao propósito de elucidar o significado de unidades da língua comum, enquanto a definição terminológica é voltada para as unidades das chamadas linguagens de especialidade. Ambos os tipos de definição, a lexicográfica e a terminológica, são exemplificados a seguir, com base em um verbete extraído de um dicionário de língua comum: ${ }^{5}$

\section{(1) martelo}

substantivo masculino

1 ferramenta provida de uma cabeça de ferro ou outro material forte e pesado, presa a um cabo e us. esp. para pregar pregos. $[\ldots]$

7 Rubrica: capoeira golpe violento em que o capoeirista usa o dorso do pé para golpear o adversário no rosto ou no tronco $[\ldots]$

11 Rubrica: música acessório que percute as cordas do piano (HOUAISS, 2009, adaptado).

Acima, a definição em 1 é lexicográfica. Já as definições em 7 e 11, marcadas com a rubrica das respectivas áreas de especialidade (i.e., capoeira e música), são exemplos de definições terminológicas.

O objeto sob estudo neste artigo é precisamente a definição terminológica. A motivação e a justificativa para este trabalho residem na observação, ainda atual, de que são insuficientes as reflexões teóricas sobre esse tipo de definição, assim como os conhecimentos dos lexicógrafos a respeito de como ela deve ser elaborada (BESSÉ, 1997, p. 63). Toma-se como ponto de partida a observação de Ferreira (2000, p. 66) de que "a questão da definição é nuclear à terminologia", e, com isso, tem-se como objetivo primordial refletir sobre a definição terminológica, além de delinear as propriedades relevantes desse tipo de definição, em comparação à definição lexicográfica, com vistas a consubstanciar o trabalho do terminógrafo com uma proposta simples de modelo de definição terminológica.

\footnotetext{
${ }^{5} \mathrm{O}$ exemplo mostra, portanto, que a definição terminológica não está limitada apenas a dicionários ou repertórios especializados.
} 
Ressalta-se, no que diz respeito à escolha dos verbetes propriamente ditos a serem discutidos, que este artigo aborda primordialmente palavras pertencentes à categoria verbal. Essa escolha justifica-se no âmbito de um projeto maior de descrição de verbos pertencentes a linguagens de especialidade e de afirmação do estatuto terminológico de alguns verbos do português brasileiro (COSTA, 2008, 2009), visto que boa parte dos trabalhos em terminologia privilegia a categoria nominal (em geral, a mais numerosa).

Com relação à metodologia empregada, este trabalho, de caráter descritivo e analítico, é baseado em revisão de literatura, bem como na análise de definições lexicográficas de cinco obras - (i) Oxford English dictionary; (ii) Cambridge dictionary; (iii) Dicionário de usos do português do Brasil (DUP); (iv) Dicionário Houaiss da língua portuguesa; e (v) Wordnik online dictionary. Este artigo orienta-se, ainda, pelos procedimentos metodológicos do "Roteiro para avaliação de dicionários e glossários científicos e técnicos", de Faulstich (2011), que visa a oferecer meios de "sistematizar as informações contidas em uma obra lexicográfica ou terminográfica" (FAULSTICH, 2011, p. 1). Assim, pretende-se investigar, na prática, como se elabora uma definição lexicográfica, de modo a consubstanciar um modelo simples e conciso de definição terminológica, proposto a seguir, em (2):

\section{(2) ESTRUTURA DA DEFINIÇÃO TERMINOLÓGICA}

$\{[+$ expressão verbal que elucide o conceito do verbo em questão] (+/- argumentos do verbo) ( $+/$ - lugar, finalidade, função) (+ exemplo)\}

O artigo tem a seguinte organização: esta seção introdutória provê uma visão geral do tema sob estudo; a seção 2 apresenta algumas considerações gerais sobre a definição lexicográfica e a definição terminológica; a seção 3 aprofunda o conceito de definição; a seção 4 introduz a análise propriamente dita de algumas definições lexicográficas das obras supracitadas; a seção 5 apresenta a proposta de modelo de definição terminológica. Finalmente, a seção 6 conclui o artigo, retomando a importância da definição tanto para a lexicografia quanto para a terminologia, bem como as características básicas que uma definição satisfatória deve apresentar. 


\section{Considerações gerais sobre a definição lexicográfica e a definição terminológica}

Como se pode depreender do exemplo (1), a definição lexicográfica e a terminológica são similares. Basta observar que, nesse exemplo, as definições 1 e 11 para 'martelo' partem de um hiperônimo ${ }^{6}$ (i.e., 'ferramenta' e 'acessório') e descrevem a função do objeto em questão. Nessa direção, Bessé (1997, p. 72) observa não haver uma distinção categórica entre os dois tipos de definição, como descrito no fragmento seguinte:

[n]a falta de experiência, tradição e bases teóricas adequadas, terminógrafos têm se inspirado na Lexicografia. Em contrapartida, lexicógrafos, frequentemente, têm sido terminógrafos sem saber. Como resultado da incorporação de um número significante de termos especializados na língua geral, até os dicionários mais ortodoxos devotam um espaço considerável aos termos técnicos, científicos, econômicos, etc.

Uma breve consulta a dicionários de língua comum no português brasileiro (PB), como o Novo dicionário Aurélio ou o Dicionário Houaiss da língua portuguesa, por exemplo, é suficiente para atestar esse fato. Observa-se que ambos os dicionários trazem em seu prefácio uma lista considerável de siglas e abreviaturas de áreas de especialidade, que tipificam certos vocábulos como termos (ver exemplo (1), que ilustra esse fato). A respeito da definição terminológica propriamente dita, Bessé (1997, p. 67) destaca o seguinte:

uma definição é uma operação que consiste em determinar todas as características que identificam a intensão do conceito. O resultado final dessa operação é uma proposição que declara a equivalência entre o termo e todas as características que o definem. Como na Lexicografia, a definição deve se aplicar ao termo definido e excluir todos os outros sentidos.

Segundo Pavel e Nolet (2002, p. 23), "a definição terminológica é uma forma lexicográfica sucinta que descreve os traços semânticos distintivos de um conceito". Para os autores:

${ }^{6}$ A definição do termo 'hiperônimo’ é apresentada logo a seguir. 
a definição terminológica é um enunciado sucinto que expõe de forma clara o significado de um conceito especializado. Começa com uma palavra que identifica a classe mais ampla, o genérico a que pertence o conceito, especificando, em seguida, os traços ou características essenciais e distintivas (PAVEL; NOLET, 2002, p. 24).

A noção de genérico ou de classe mais ampla alude ao conceito de hiperônimo (que, grosso modo, seria o elemento mais alto em uma hierarquia de conceitos). Por exemplo, note-se a reprodução (parcial) do seguinte verbete, com grifo nosso:

\section{(3) brinco}

substantivo masculino

$[\ldots]$

4. peça de adorno que se usa presa ao lobo da orelha ou pendente deste.

[...] (HOUAISS, 2009).

A expressão em destaque representa o hiperônimo (i.e., "peça de adorno"), do qual a palavra 'brinco' é um hipônimo. Outros hipônimos seriam 'anel', 'colar', 'pulseira' etc. Como observado por Vilarinho (2013, p. 238), "[p]odemos notar que os hipônimos são membros da mesma categoria do hiperônimo". Percebe-se que iniciar o texto da definição com o emprego de um hiperônimo é prática difundida no âmbito da Lexicografia (cf. (1) e (3)). ${ }^{7}$

No que concerne aos repertórios terminológicos, é importante não se perder de vista também o fato de que estes podem ser de naturezas diversas. Por exemplo, as áreas esportiva, jurídica, científica, entre outras, apresentam particularidades quanto às exigências de exatidão do seu vocabulário próprio. Nesse sentido, a questão do 'contexto' ganha destaque.

Ao analisar a relação entre as unidades de um vocabulário terminológico e o contexto em que ocorrem, Dubuc e Lauriston (1997) estabelecem a distinção entre o termo in vivo e o termo in vitro. Segundo os autores, o primeiro diz respeito ao termo em si, "componente in vivo

\footnotetext{
${ }^{7}$ A esse respeito, Faulstich (2013, p. 1) observa: “[é] de conhecimento que a forma canônica da definição de um termo segue o modelo gênero + espécie."
} 
de uma linguagem de especialidade"; e o segundo, ao "termo entrada, a imagem in vitro de um termo que é colocado em um trabalho de compilação terminológica como um dicionário, vocabulário ou léxico" (DUBUC; LAURISTON, 1997, p. 80). De acordo com os autores, o 'contexto' é o discurso no qual o termo está incorporado (DUBUC; LAURISTON, 1997, p. 81), e os terminólogos devem focar na forma in vivo do termo, ou seja, na sua realização dentro de um contexto. $\mathrm{Na}$ mesma direção, Ferreira (2000, p. 69) destaca que "[n]ão podemos, em terminologia, raciocinar sobre unidades isoladas, esquecendo a importância do contexto e do sistema". No que se segue, embora se reconheça a importância do contexto e do sistema, este artigo aborda particularmente a forma in vitro dos termos, isto é, como o termo é (ou deve ser) definido.

\section{Aprofundando o conceito de definição}

Bessé (1997) indaga se existe, de fato, uma definição terminológica e como ela se distinguiria de outras modalidades de definição (e.g., a lexicográfica ou a enciclopédica, discutidas adiante). A caracterização bem-sucedida do que é uma definição terminológica e de quais pré-requisitos ela deve atender é um ponto de partida para o estabelecimento dos princípios de sua formulação. Nesse sentido, este artigo alinha-se às ideias de Finatto (1998, p. 212) sobre a definição terminológica, descritas a seguir:

podemos considerar que a definição terminológica é um lugar de encontro entre o aspecto conceptual e o lingüístico, uma vez que o texto da definição tem a função de descrever as características que delimitam um conceito e a função de particularizá-lo num determinado sistema conceptual ou domínio.

Adicionalmente, Ferreira (2000, p. 67) chama a atenção para o fato de que "há que se diferenciar - devido em especial a uma freqüente confusão -, a definição da descrição". Na definição, devem estar explícitos todos os traços conceituais pertinentes que um termo evoca. Já na descrição, podem estar presentes traços pertinentes e traços característicos. Para Cabré (1993, p. 200), a descrição do conceito se dá pelo "conjunto das características inter-relacionadas que descrevem 
essencial e complementarmente uma classe de objetos da realidade". De acordo com a autora, há dois procedimentos possíveis: a compreensão e a extensão. A descrição por compreensão se baseia na ordenação das características gerais às mais específicas em um processo lógico que, de acordo com Cabré (1993, p. 201), vai "do gênero à espécie" (cf. discussão sobre as relações de hiperonímia na seção anterior). A descrição por extensão consiste em enumerar todas as realizações possíveis de um conceito.

Bessé (1997, p. 70-71) introduz algumas noções básicas que devem ser consideradas na elaboração de uma boa definição terminológica:

(i) Adefinição terminológica, a exemplo da definição lexicográfica, não precisa necessariamente ser completa, mas suficiente para distinguir um conceito de outro.

(ii) A definição é uma operação que consiste em determinar o conjunto dos caracteres que entram na compreensão de um conceito. O resultado dessa operação é uma proposta que enuncia uma equivalência entre um termo (ele definido) e o conjunto de caracteres que o definem.

(iii) A definição terminológica é elaborada por meio de referência à coisa que o signo denota (i.e., é referencial). A entrada não é propriamente o termo, mas, antes, a coisa descrita e, mais precisamente, a sua representação conceitual.

(iv) A definição designa uma classe geral à qual pertence o conceito definido, ao mesmo tempo em que especifica o que o distingue dos outros conceitos da mesma classe.

(v) A definição pode ser substancial e descrever o objeto, enumerar as suas propriedades. Pode, igualmente, não se limitar unicamente ao seu uso.

(vi) A definição pode conter ilustrações.

No que diz respeito à redação propriamente dita das definições, Pavel e Nolet (2002, p. 24-26) postulam quatro modelos, a saber: 
(I) Definição por gênero próximo e diferença específica. Exemplos:

(i) "periférico: em um sistema de processamento de dados, tudo o que não é o microprocessador e seus satélites imediatos [...] e que permite a comunicação em linha ou em diferido com o exterior" (PAVEL; NOLET, 2002, p. 25).

(ii) "periférico de saída: periférico que permite ao usuário ter acesso aos dados contidos no sistema" (PAVEL; NOLET, 2002, p. 25).

(II) Definição por função. Exemplo:

"impressora matricial: impressora que produz imagens a partir de pontos" (PAVEL; NOLET, 2002, p. 25). ${ }^{8}$

(III) Definição por descrição de uma ação, enumerando suas partes ou etapas. Exemplo:

"impressora a laser: impressora que funciona pelo mesmo princípio que as fotocopiadoras. A imagem da página que se tem de imprimir transfere-se a um tambor magnético. A tinta deposita-se neste tambor e depois sobre a página de impressão" (PAVEL; NOLET, 2002, p. 25).

(IV) Definição por paráfrase sinonímica. Exemplo:

"quadrado: que tem forma quadrangular" (PAVEL; NOLET, 2002, p. 26).

Strehlow (1997) propõe um modelo visual para apresentar a estrutura e o conteúdo das definições. $\mathrm{O}$ autor argumenta em favor do uso imaginativo de amostras de definições, em vez da criação de modelos rígidos de definições escritas, e apresenta o modelo de Putnam, de 1975. Esse modelo inclui quatro categorias a serem levadas em consideração no processo de elaboração de uma definição: (i) marcadores sintáticos; (ii) marcadores semânticos, (iii) propriedades estereotípicas, e (iv) extensão. No quadro abaixo segue a amostra da definição de 'tigre':

\footnotetext{
${ }^{8}$ Um parecerista anônimo sugere a reavaliação deste exemplo, ao observar que também se trata de uma definição por gênero próximo e diferença específica. Como o exemplo em questão é fielmente citado de Pavel e Nolet (2002), limito-me a mantê-lo e a registrar a observação supracitada, com a qual concordo.
} 
QUADRO 1

Modelo de definição

\begin{tabular}{l|l|l|l}
\hline $\begin{array}{l}\text { Marcadores } \\
\text { sintáticos }\end{array}$ & $\begin{array}{l}\text { Marcadores } \\
\text { semânticos }\end{array}$ & $\begin{array}{l}\text { Propriedades } \\
\text { estereotípicas }\end{array}$ & Extensão \\
\hline Nome concreto & $\begin{array}{l}\text { Tipo natural } \\
\text { Animal }\end{array}$ & $\begin{array}{l}\text { Grande } \\
\text { Carnívoro }\end{array}$ & $\begin{array}{l}\text { Panthera } \\
\text { tigris }\end{array}$ \\
& Mamífero & $\begin{array}{l}\text { Origem asiática } \\
\text { Listras negras }\end{array}$ \\
& & & \\
\hline
\end{tabular}

Fonte: STREHLOW, 1997, p. 75.

A respeito da definição terminológica propriamente dita, Vilarinho (2013, p. 40) destaca que esta pode ser exemplificada em normas da ABNT:

[u]m exemplo disso é a definição do termo complexo colchão de espuma flexível de poliuretano, definido como "bem de consumo destinado ao repouso humano, constituído, parcial ou integralmente, por lâmina(s) flexível(is) de poliuretano, devidamente revestido" (NBR 13579, 2011, p. 1). Lâmina(s) flexível(is) de poliuretano são termos relativos à configuração do colchão. Mas, para a melhor compreensão da definição, é necessário saber o significado dos termos que representam o conceito em questão.

Finalmente, Faulstich (2013, grifo da autora) observa que "[n] uma proposição lexicográfica, aquela que aparece como definição nos dicionários, o significado de $\mathrm{Y}$ está contido em $\mathrm{X}$ porque o que interessa ao consulente de um dicionário é compreender o que é o objeto $X$ ”. Notase que essa estrutura da definição não é alterada quando se considera o âmbito das terminologias. Tomando-se um exemplo da autora: "na terminologia da área da saúde, [...] 'traqueotomia' (X) é intervenção cirúrgica na traqueia (Y) [...]" (FAULSTICH, 2013). Além desse molde de definição, que indica "o que é”, há também o molde que indica "para que serve". Por exemplo, ainda no âmbito da terminologia da área da saúde "“"pinça = utensílio que serve para pegar objeto; vacina = substância que serve para imunizar o organismo" (FAULSTICH, 2013). ${ }^{9}$

\footnotetext{
${ }^{9}$ Atente-se, mais uma vez, para a estrutura da definição, sistematizada em termos de gênero > espécie ou hiperônimo > hipônimo.
} 
Reafirma-se, assim, a ideia de que não é possível estabelecer uma distinção nítida e categórica entre a definição lexicográfica e a terminológica, como discutido na seção 2 . No entanto, as noções básicas de Bessé (1997), expressas anteriormente nos tópicos de (i) a (vii), e as observações de Faulstich (2013) acerca das características da definição no âmbito das terminologias são relevantes para se delinear um modelo de definição terminológica que sirva às particularidades das linguagens de especialidade e que seja capaz de orientar o trabalho do terminógrafo. Dessa forma, adota-se o trabalho desses autores como um guia para a elaboração desse modelo de definição.

\section{Análise de algumas definições lexicográficas}

Nesta seção, analisa-se amostras de definições de cinco dicionários, a saber:
(i) Oxford English dictionary;
(ii) Cambridge dictionary;
(iii) Dicionário de usos do português do Brasil (DUP);
(iv) Dicionário Houaiss da língua portuguesa, e
(v) Wordnik online dictionary.

O objetivo desta análise é examinar as principais propriedades e características da definição lexicográfica presente em diferentes obras; estabelecer uma comparação entre elas, observando seus pontos de convergência ou divergência. Com isso, pretende-se estabelecer certas diretrizes a serem seguidas na elaboração da definição terminológica. Quanto à justificativa para a escolha dessas obras, cabe destacar que os dicionários da língua inglesa Oxford e Cambridge vêm de longa tradição lexicográfica. Sua escolha, portanto, justifica-se por serem obras notórias e consagradas. Assim, é seguro considerar a estrutura de suas definições com vistas a substanciar um modelo adequado de definição terminológica. No que diz respeito aos dicionários da língua portuguesa, ressalta-se que o DUP é um dicionário estruturado em termos de descrição sintática e regras de contexto, o que confere "coerência e exaustividade ao dicionário" (BORBA, 1996, p. 16). Com isso, essa obra lexicográfica também é adequada para investigar aspectos relevantes da definição. Igualmente, o dicionário Houaiss é uma obra notória e respeitada, de ampla consulta 
no Brasil. Destaca-se, ainda, que o dicionário faz uso de uma "interface gráfica desenhada para permitir de forma clara e agradável a obtenção de diferentes informações do verbete consultado" (HOUAISS, 2009). ${ }^{10}$ Finalmente, o dicionário on-line Wordnik foi escolhido por se tratar de um projeto lexicográfico original, moderno e inovador. Trata-se do maior dicionário on-line da língua inglesa, por número de palavras. Um dos aspectos singulares do projeto é o fato de que as definições trazidas pela obra vêm de múltiplas fontes, o que permite ao consulente obter uma gama variada de informações sobre determinada palavra. Sua escolha justifica-se uma vez que esta é uma obra pioneira, que aponta tendências futuras para a elaboração de repertórios lexicográficos, que podem ser aplicadas no âmbito das terminologias.

Finalmente, no que diz respeito à escolha dos verbetes propriamente ditos, como estabelecido na introdução deste artigo, a palavra-entrada escolhida pertence à categoria verbal, especificamente $o$ verbo play/' jogar'. A escolha dessa categoria justifica-se no âmbito de um projeto maior que busca descrever os verbos pertencentes a linguagens de especialidade, bem como o estatuto terminológico de alguns verbos do PB (COSTA, 2008, 2009). Além disso, como mencionado, a maioria dos trabalhos em terminologia privilegia a categoria nominal, havendo, assim, uma lacuna na descrição de verbos. Contudo, destaca-se que o modelo de definição terminológica apresentado neste artigo pode ser facilmente adaptado para outras categorias. No que concerne especificamente à escolha do verbo em questão, destaca-se que o intuito foi o de selecionar um verbo relativamente polissêmico, de modo que um único verbete permitisse o cotejo de diferentes acepções ou definições, tornando, assim, o trabalho mais produtivo.

\subsection{Oxford English dictionary}

Segue o verbete de play/ 'jogar’:

play

- verb 1 engage in games or other activities for enjoyment rather than for a serious or practical purpose. 2 take part in (a sport or contest). 3 compete against. 4 take a specified position in a sports

\footnotetext{
${ }^{10}$ Informações extraídas do manual do usuário do dicionário Houaiss (versão eletrônica).
} 
team. 5 represent (a character) in a play or film. 6 perform on or have the skill to perform on (a musical instrument). 7 produce (notes) from a musical instrument; perform (a piece of music). 8 move (a piece) or display (a playing card) in one's turn in a game. 9 make (a record player, radio, etc.) produce sounds. 10 be cooperative: he needs financial backing, but the banks won't play (OXFORD..., c2016, grifo nosso).

Nesse exemplo do dicionário Oxford, todas as dez acepções registradas para o verbo play são iniciadas por expressões verbais com a função de explicitar o traço mais marcante do conceito atribuído ao verbo na acepção em questão. A seguir, as acepções 5 e 9 são detalhadas:

\section{(4) jogar/tocar ${ }^{11}$ verbo \\ $[\ldots]$}

5. representar (um personagem) em uma peça de teatro ou em um filme.

$[\ldots]$

9. fazer que (um toca-discos, rádio, etc.) produza sons (OXFORD..., c2016, tradução nossa, adaptado).

Tem-se a seguinte estrutura para cada uma dessas acepções:

(5) a. Definição: $\{[+$ expressão verbal: representar $]+($ complemento do verbo: um personagem) + (lugar: em uma peça ou filme) $\}$

b. Definição: $\{[+$ expressão verbal: fazer $]+$ (complemento do verbo: um toca discos, rádio, etc.) + (finalidade: produzir som) $\}$

De maneira geral, a estrutura da definição é a seguinte:

(6) ESTRUTURA DA DEFINIÇÃO LEXICOGRÁFICA (OXFORD) $\{[+$ expressão verbal que elucida o conceito $](+/-$ complemento do verbo) (+/- lugar, finalidade, função, etc.) +/- exemplo\}

\footnotetext{
${ }^{11}$ Observe-se que, no português, o verbo play pode ser traduzido por dois itens lexicais distintos (i.e., 'jogar' ou 'tocar'), a depender de seu contexto de ocorrência.
} 


\subsection{Cambridge dictionary}

A seguir, o verbete de play/'tocar, atuar ou fazer papel de':

play (PRODUCE SOUNDS/PICTURES)

verb

1 to perform music on an instrument or instruments: He learned to play the clarinet at the age of ten.

2 to (cause a machine to) produce sound or a picture: Play the last few minutes of the video again.

play (ACT)

verb

1 to perform an entertainment or a particular character in a play, film or other entertainment: In the film version, Kenneth Branagh played the hero.

2 to behave or pretend in a particular way, especially in order to produce a particular effect or result: to play dead/dumb (CAMBRIDGE... c2016, grifo nosso).

No dicionário Cambridge, as definições seguem padrão similar ao do dicionário Oxford. Entretanto, apresenta aspectos distintivos, particularmente quanto ao registro do verbo play em verbetes separados, com as acepções agrupadas de acordo com a ideia geral atribuída a esse verbo, registrada entre parênteses (i.e., "produzir sons/ imagens" e "atuar"). Além disso, esse dicionário é rico em exemplos, que aparecem em todas as acepções de play. A seguir, a primeira definição de cada acepção é detalhada:

(7) tocar (produzir sons/imagens)

1 executar uma música em um instrumento ou em instrumentos: Ele aprendeu a tocar clarinete aos dez anos.

atuar (ou fazer o papel de) (atuar/performar)

1 atuar um tipo de entretenimento ou personagem particular em uma peça de teatro, filme ou outro tipo de entretenimento: $\mathrm{Na}$ versão do filme, Kenneth Branagh atuou como o (ou fez o papel de) herói (CAMBRIDGE..., c2016, tradução nossa, adaptado). ${ }^{12}$

\footnotetext{
${ }^{12}$ Novamente, destaca-se o uso de expressões distintas (i.e., 'tocar' e 'atuar/fazer o papel de') para captar, no português, o que o inglês denota com um mesmo item lexical (i.e., play).
} 
Tem-se a seguinte estrutura para cada uma dessas acepções:

(8) a. Definição: $\{[+$ expressão verbal que elucida o conceito: tocar] + (complemento do verbo: música em um instrumento ou instrumentos $)+($ exemplo $)\}$

b. Definição: $\{[+$ expressão verbal que elucida o conceito: fazer (o papel de)] + (complemento do verbo: um personagem) + (lugar: em uma peça, filme) + (exemplo) $\}$

De maneira geral, a estrutura da definição é a seguinte:

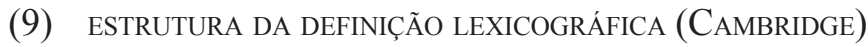
$\{[+$ expressão verbal que elucida o conceito $](+/-$ complemento do verbo) (+/- lugar, finalidade, função, etc.) (+ exemplo)\}

\subsection{Dicionário de usos do português do Brasil (DUP)}

Na sequência, o verbete de 'jogar’ (i.e., uma das acepções de play): jogar V • 1 lançar; atirar; arremessar: jogou o paletó sobre o ombro esquerdo; joga dentro da panela umas ervas $\mathbf{2}$ impelir; empurrar: A miséria jogou as meninas para a rua 3 colocar; pôr: O fato de fabricar peças joga-o numa relação de classes bem determinada 4 instigar: Quiseste jogar o povo contra os nobres e contra os padres $\mathbf{5}$ atribuir: Então você joga a culpa no Departamento de Trânsito 6 lançar com ímpeto: Laércio joga na minha cara que sou um trouxa 7 apostar: Vitoriano deu para jogar em cavalos $\mathbf{8}$ manipular; manobrar: A Inglaterra jogava então com um grande trunfo 9 arremessarse; atirar-se: $O$ homem joga-se por terra 10 disputar uma partida: Demorei um pouco porque fiquei jogando damas com o porteiro 11 dirigir; lançar: jogara seu olhinho amarelo como um sol triste em cima de mim 12 manejar búzios como arte de previsão do futuro: aproximaram-se da mesa de Suzy e conversaram sobre a promessa que Suzy fizera de jogar búzios naquela noite 13 balançar; oscilar: Sente-se que o avião joga e que os passageiros estão apreensivos 14 combinar: mesabanqueta capitonada no mesmo jacquard que joga com um tapete Kilin afegão $\mathbf{1 5}$ rogar: viessem as pragas que o povo joga no pobre do Guedinho (BORBA, 2002). 
O Dicionário de usos do português do Brasil (DUP) traz definições sucintas, com base na equivalência com outros verbos da língua, como observado nos exemplos anteriores..$^{13} \mathrm{O}$ sentido particular dos verbos é elucidado com base no seu contexto de uso, a partir de exemplos dados para todas as acepções registradas, como se depreende da primeira definição:

(10) jogar [...] lançar; atirar; arremessar: jogou o paletó sobre o ombro esquerdo; joga dentro da panela umas ervas (BORBA, 2002, adaptado).

A estrutura da definição é a seguinte:

(11) Definição: \{[+ expressão verbal equivalente que elucida o conceito do verbo: lançar; atirar; arremessar] (+ exemplo: jogou o paletó sobre o ombro esquerdo; joga dentro da panela umas ervas.) \}.

De maneira geral, a estrutura da definição é a seguinte:

(12) ESTRUTURA DA DEFINIÇão LEXICOGRÁfiCA (DUP)

$\{[+$ expressão verbal equivalente que elucida o conceito do verbo] $(+$ exemplo)\}

\subsection{Dicionário Houaiss da língua portuguesa}

A seguir, o verbete de 'atuar' (i.e., uma das acepções de play):

\section{atuar}

verbo intransitivo

1 exercer ação ou atividade; agir, obrar, operar

Exs.: foi necessário a. junto às autoridades, o executivo deve a. de forma ágil

predicativo

2 ter como função

Ex.: ela atuava como porta-voz do grupo

${ }^{13}$ Um parecerista anônimo observa que não se trata apenas de definições sucintas, mas de definições sinonímicas, e que alguns autores da lexicografia não consideram a sinonímia um tipo de definição, enquanto outros a consideram como um mecanismo útil. 
transitivo indireto predicativo e intransitivo

3 Rubrica: cinema, teatro, televisão.

desempenhar um papel como ator (em); representar

Exs.: atuou brilhantemente no papel de Hamlet, a veterana atriz atuou como Fedra, a novata atua muito bem

transitivo indireto

4 ter influência; influenciar, influir

Ex.: o avô foi quem mais atuou em sua formação

transitivo indireto e intransitivo

5 produzir efeito

Exs.: as mudanças atuaram positivamente sobre o ritmo do trabalho, remédio que atua lentamente intransitivo

6 ter parte em um resultado; concorrer, contribuir

Ex.: o escândalo atuou para que ele perdesse votos eleitorais transitivo indireto

7 fazer pressão; constranger, coagir, pressionar

Ex.: atuou sobre a chefia para obter uma promoção (HOUAISS, 2009)

Observe-se com mais detalhe a terceira acepção, uma vez que esta traz rubrica de área de especialidade, isto é, marca o verbo 'atuar' como pertencente à terminologia das áreas de cinema, teatro e televisão.

(13) [atuar] desempenhar um papel como ator (em); representar Exs.: atuou brilhantemente no papel de Hamlet, a veterana atriz atuou como Fedra, a novata atua muito bem (HOUAISS, 2009, adaptado).

A estrutura da definição segue:

(14) Definição: $\{[+$ expressão verbal equivalente ou sinônima que elucida o conceito do verbo: desempenhar] (+ complemento do verbo: papel como ator) (+ exemplo)\}.

De maneira geral, a estrutura da definição é a seguinte:

(15) ESTRUTURA DA DEFINIÇÃo LEXICOGRÁFICA (HouAISS)

$\{[+$ expressão verbal equivalente que elucida o conceito do verbo] (+complemento do verbo) (+ exemplo) $\}$ 


\subsection{Wordnik online dictionary}

Na sequência, o verbete do verbo play:

FIGURA 1: Exemplo de verbete

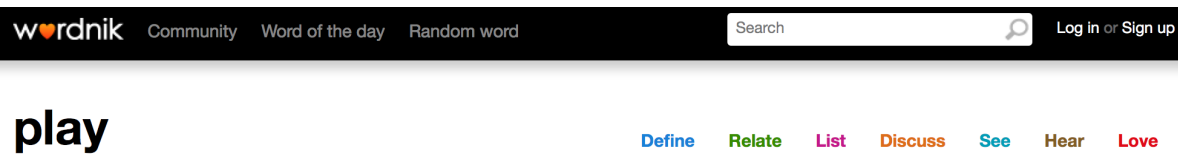

\begin{abstract}
Definitions
from The American Heritage $\left({ }^{\circ}\right.$ Dictionary of the English Language, 4 th Edition

intransitive $v$. To occupy oneself in amusement, sport, or other recreation: children playing with toys.

intransitive $v$. To take part in a game: No minors are eligible to play.

intransitive $v$. To participate in betting; gamble.

intransitive $v$. To act in jest or sport: They're not arguing in earnest, they're just playing.

intransitive $v$. To deal or behave carelessly or indifferently; toy. See Synonyms at flirt.

intransitive $v$. To behave or converse sportively or playfully.

intransitive $v$. To act or conduct oneself in a specified way: play fair; an investor who plays cautiously.
\end{abstract}

Support

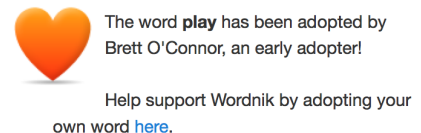
own word here.

\section{Examples}

A retreat from complexity isn't a sign of stupidity, sheeple-hood or lack of an e-peen: honestly, it's perhaps the core pleasure of play, a notion lost to some professionals and scholars who have managed to leach the "play* out of what they do.

Fonte: WORDNIK..., [s.d.]. Fac-símile.

Observa-se que este dicionário possui uma estrutura não canônica. ${ }^{14}$ Embora a figura não permita visualizar, a lista de definições (sob "Definitions") é bastante extensa e supera a de todos os outros dicionários previamente analisados. Chama-se a atenção ao menu superior direito, onde se encontra a sequência "Definir, Relacionar, Listar, Discutir, Ver, Ouvir, Amar". Ao se clicar em "Definir", o consulente é remetido à referida lista de definições; ao se clicar em "Relacionar", é

\footnotetext{
${ }^{14}$ A respeito da macro e microestrutura do dicionário, Faulstich (2010c. p. 169 apud VILARINHO, 2013, p. 37) observa que a microestrutura "'é formada pelo conjunto de informações que compõem os verbetes; é, de fato, o verbete na sua totalidade, constituído pela metalinguagem de que se provê a palavra-entrada". A macroestrutura é o "conjunto da obra, todos os aparatos de ordenação" (FAULSTICH, 2010c. p. 169 apud VILARINHO, 2013, p. 37), constitui os elementos de composição de um dicionário, tais como: prefácio, introdução, informações a respeito da organização da obra, referências bibliográficas, entre outros. Nota-se, assim, o aspecto inovador da obra Wordnik, no que concerne a ambos os aspectos.
} 
levado a uma sistematização de sinônimos, antônimos, equivalentes, hiperônimos, contextos relacionados etc.; e ao se clicar, por exemplo, em "Ver", o consulente acessa uma série de imagens que ilustram o significado do verbo play, em suas mais variadas acepções. Abaixo, (16) exemplifica uma das definições de play pelo Wordnik:

(16) brincar ocupar-se com um divertimento, esporte ou outro tipo de recreação: crianças brincando com jogos/ brinquedos (WORDNIK..., [s.d.], tradução nossa, adaptado).

A estrutura da definição é apresentada a seguir:

(17) Definição: \{[+ expressão verbal equivalente ou sinônima que elucida o conceito do verbo: ocupar-se com] (+ complemento do verbo: divertimento, esporte, recreação) (+ exemplo)\}.

De maneira geral, a estrutura da definição é a seguinte:

(18) ESTRUTURA DA DEFINIÇÃO LEXICOGRÁFICA (WORDNIK) $\{[+$ expressão verbal equivalente que elucida o conceito do verbo] (+ complemento do verbo) (+ exemplo)\}

Embora se trate de um dicionário moderno, dotado de estrutura original de disposição das informações, a estrutura da definição propriamente dita é consistente com a dos outros dicionários analisados. Nota-se que esse tipo de dicionário on-line aponta uma tendência interessante de modernização na apresentação das informações relevantes sobre uma palavra-entrada. ${ }^{15}$

Finalmente, o cotejo dessas obras lexicográficas permite constatar que, embora elas exibam diferentes formatos e finalidades (i.e., dicionário voltado para a aprendizagem de uma língua, dicionário de uso, dicionário eletrônico, dicionário on-line etc.), a estrutura das definições propriamente ditas é bastante similar. O texto da definição parte de um hiperônimo (no caso em análise, uma expressão verbal que elucida o conceito mais geral do verbo a ser definido), podendo incluir ou não os complementos do verbo, bem como descrever outras propriedades

\footnotetext{
${ }^{15}$ Esse tipo de estrutura inovadora e a sua aplicação na sistematização de repertórios terminológicos é deixada para pesquisas futuras.
} 
relevantes para particularizar e delimitar o conceito do item em questão (i.e., lugar, finalidade, função, etc.). Além disso, o texto da definiç̧ão, em geral, traz consigo exemplos de uso. Tomando essa estrutura básica como ponto de partida, a seção a seguir aborda as particularidades da definição terminológica.

\section{Modelo de definição terminológica}

Em seu "Roteiro para avaliação de dicionários e glossários científicos e técnicos", Faulstich (2011, p. 9) discute alguns aspectos da definição que orientam este trabalho:

A definição é, por regra, constituída de um enunciado de uma só frase. Se se considerar, do ponto de vista da estrutura, que uma frase é um enunciado que começa com uma letra maiúscula e termina num ponto, a definição pode ser, grosso modo, vista como tal. Do ponto de vista linguístico, a definição é um enunciado que expõe de forma sumária e clara as características genéricas e específicas de um objeto, inserindo-o num determinado campo do conhecimento. Do ponto de vista lógico, a definição é uma equação que opera a igualdade entre a palavra entrada, que representa o objeto, e a predicação, que é o argumento, com vistas a atribuir as mesmas propriedades à palavra-entrada e à predicação.

A autora destaca, ainda, um ponto não discutido até aqui neste artigo, que, não obstante, é relevante no âmbito da definição terminológica: a chamada variante da definição. De acordo com Faulstich (2011, p. 7), "a variante da definição é uma estrutura textual que apresenta alguma diferença na forma de dizer o mesmo conceito", que não deve ser confundida com polissemia ou homonímia.

Além desses aspectos da definição terminológica, são levados em consideração alguns princípios apresentados por Pavel e Nolet (2002, p. 26, adaptado):

(i) previsibilidade: a definição insere o conceito em uma árvore conceitual

(ii) simplicidade: a definição é concisa e clara, [...] constituída por apenas uma frase

(iii) enunciado afirmativo: a frase diz o que é o conceito, não o que não é

(iv) não circularidade: a definição não remete à (sic) outra definição. 
Assim, com base nas propriedades da definição lexicográfica discutidas na seção anterior e nos princípios e nas características próprias da definição terminológica discutidos ao longo deste trabalho (ver CABRÉ, 1993; BESSÉ, 1997; STREHLOW, 1997; PAVEL; NOLET, 2002; FAULSTICH, 2011, 2013), propõe-se o seguinte modelo mínimo, simples e conciso de definição terminológica:

(19) ESTRUTURA DA DEFINIÇÃO TERMINOLÓGICA

$\{[+$ expressão verbal que elucide o conceito do verbo em questão] (+/- argumentos do verbo) (+/- lugar, finalidade, função) (+ exemplo)\}

Como discutido anteriormente, este modelo é pensado para a definição de verbos que possuem estatuto de termo (i.e., verbos que pertencem ao vocabulário de determinada área de especialidade). Entretanto, é evidente que a estrutura em (19) é facilmente adaptável a outras classes. A seguir, exemplifica-se a aplicação desse modelo de definição a uma série de verbos pertencentes a diversas linguagens de especialidade: ${ }^{16}$

(20) $\operatorname{rodar}$ (Cinema): registrar cenas em filme, filmar. O diretor rodou o seu último filme em Roma.

(21) tabelar (Futebol): fazer uma jogada com dois (ou mais) jogadores na qual a bola passa do pé de um jogador ao outro, fazer uma tabela. Marta tabelou com Formiga antes de marcar o gol.

(22) reduzir (Automobilismo): executar movimento que aumenta a tração da marcha de um automóvel ou outro meio de transporte. Ao ver o animal na pista, reduziu a marcha.

(23) rasgar (Música): Tocar (em um violão ou em uma viola) o estilo musical rasgado. Todos vieram ouvir o músico rasgando a viola.

(24) possear (Jurídica): Ocupar ou tomar posse de uma extensão de terra. O grupo posseou as terras improdutivas.

\footnotetext{
${ }^{16}$ Os exemplos provêm de Costa (2008).
} 
Essa pequena amostra de verbos ilustra a aplicação do modelo de definição terminológica em favor do qual este artigo argumenta.

\section{Conclusão}

Este artigo abordou a questão da definição no âmbito das práticas lexicográficas e terminográficas. A partir da observação de Ferreira (2000, p. 66) de que "a questão da definição é nuclear à terminologia", teve-se como objetivo primordial refletir sobre a definição terminológica, além de delinear suas propriedades relevantes, em comparação à definição lexicográfica, com vistas a apresentar uma proposta simples de modelo de definição terminológica.

Do ponto de vista teórico, o artigo conclui não ser possível estabelecer uma distinção nítida e categórica entre a definição lexicográfica e a terminológica. Essa questão é explicitamente discutida na literatura (ver BESSÉ, 1997) e o registro de alguns vocábulos apresentados neste artigo (cf. exemplos (1) e (3)) corrobora esse fato ao mostrar que os dois tipos de definição coexistem em obras lexicográficas de língua comum. Nesse contexto, a rubrica da área de especialidade tem o importante papel de tipificar um vocábulo como termo e situar a definição no âmbito das linguagens de especialidade, como mostrado em (1).

De maneira geral, independentemente do tipo de definição, constata-se que há certas diretrizes a serem observadas na elaboração de uma definição. Por exemplo, um princípio importante é o de que o texto da definição deve seguir o modelo gênero + espécie, conforme apontado por Faulstich (2013) e discutido ao longo deste trabalho. A comparação estabelecida entre diferentes dicionários de língua comum, apresentada na seção 4, mostra esse princípio em prática. Nessa seção, concluiu-se que a estrutura básica da definição seguida por obras lexicográficas de excelência parte do modelo gênero + espécie e elucida e delimita o conceito do vocábulo em questão (no caso, um verbo) com a inclusão de outras informações importantes, como complementos do verbo, lugar, finalidade, função e exemplos.

No que concerne especificamente ao âmbito dos estudos terminológicos, o artigo demonstrou, com base na literatura discutida (CABRÉ, 1993; BESSÉ, 1997; STREHLOW, 1997; PAVEL; NOLET, 2002; FAULSTICH, 2011, 2013) e na observação dos verbetes supracitados, que uma definição terminológica satisfatória deve: 
(i) seguir o modelo gênero + espécie (isto é, partir de um hiperônimo e ser organizada de forma hierárquica);

(ii) seguir o princípio da simplicidade, ou seja, ser estruturada de maneira clara e concisa, em uma proposição declarativa e afirmativa;

(iii) incluir a indicação da área de especialidade e/ou quaisquer informações que sejam relevantes para elucidar o contexto de uso do termo em questão;

(iv) incluir informações relevantes para delimitar o conceito em questão e auxiliar o consulente a compreender o termo em uso (por exemplo, indicar o que é o objeto, para que serve, sua finalidade primordial, onde é usado, por quem é usado, etc.);

(v) sempre que possível, incluir exemplos.

Apoiado nessas diretrizes, o artigo propôs uma estrutura da definição terminológica (25a), cuja aplicação pode ser demonstrada pelo exemplo adicional em (25b):

(25) a. ESTRUTURA DA DEFINIÇÃO TERMINOLÓGICA

$\{[+$ expressão verbal que elucide o conceito do verbo em questão] (+/- argumentos do verbo) (+/- lugar, finalidade, função) (+ exemplo)\}

b. cozinhar (Jornalismo): 1. Preparar reportagens para publicação em um jornal. O jornalista cozinhou o texto às pressas para a publicação.| (Jornalismo, pejorativo): 2. Reescrever uma reportagem já publicada em outro veículo jornalístico. Um bom jornalista não cozinha textos, mas pesquisa e produz reportagens originais.

Finalmente, este artigo teve o objetivo investigar, de maneira prática e concreta, como se estrutura a definição lexicográfica, de modo a consubstanciar um modelo simples e conciso de definição terminológica, ora apresentado, com a finalidade de contribuir para o trabalho de terminógrafos.

\section{Agradecimentos}

Às professoras Enilde Faulstich e Michelle Vilarinho, pelas inúmeras discussões a respeito do tema tratado neste trabalho. Aos pareceristas anônimos e editores da revista Caligrama, pelos comentários e sugestões que melhoraram substancialmente a primeira versão deste artigo. 


\section{Referências}

BESSÉ, B. D. Terminological definitions. In: WRIGHT, S. E.; BUDIN, G. (Org.). Handbook of terminology management. Amsterdam, Philadelphia: John Benjamins Publishing Company, 1997. v. 1, p. 63-74.

BORBA, F. S. et al. Dicionário de usos do português do Brasil. São Paulo: Editora Ática, 2002.

BORBA, F. S. Uma gramática de valências para o português. São Paulo: Editora Ática, 1996.

CABRÉ, M. T. La terminologia. Teoria, metodologia, aplicaciones. Barcelona: Antártida, Empúries, 1993.

CAMBRIDGE DICTIONARY. [S.1.]: Cambridge University Press, c2016. On-line. Disponível em: <http://dictionary.cambridge.org/>. Acesso em: 10 abr. 2016.

COSTA, B E. A categoria do verbo em terminologia. In: ENCONTRO DE LETRAS DA UCB, 7., 2009, Brasília, DF. Anais... Brasília: UCB, 2009. p. 60-86.

COSTA, B. E. Brasileirismos terminológicos: estado de verbos em ação e processo. 2008. 198 p. Dissertação (Mestrado em Linguística) - Instituto de Letras, Universidade de Brasília, Brasília, 2008.

DUBUC, R.; LAURISTON, A. Terms and contexts. In: WRIGHT, S. E.; BUDIN, G. (Org.). Handbook of terminology management. Amsterdam, Philadelphia: John Benjamins Publishing Company, 1997. v. 1,.p. 80-87.

FAULSTICH, E. Avaliação de dicionários: uma proposta metodológica. Organon: Revista da Faculdade da Filosofia da Universidade Federal do Rio Grande do Sul, Porto Alegre, v. 25, n. 50, não paginado, 2011.

FAULSTICH, E. Características conceituais que distinguem o que é de para que serve nas definições de terminologias científica e técnica. Trabalho apresentado no IX Encontro Intermediário do Grupo de Trabalho de Lexicologia, Lexicografia e Terminologia da ANPOLL. Caxias do Sul, RS, 2013. Não publicado. Não paginado. Disponível em: $<$ http://bit.ly/2iJ5UGI > Acesso em: 9 abr. 2016. 
FERREIRA, A. M. D. A. Para um vocabulário fundamental da obra de Milton Santos (com equivalência em francês). 2000. Tese (Doutorado em Linguística) - Faculdade de Filosofia, Letras e Ciências Humanas, Universidade de São Paulo, São Paulo, 2000.

FINATTO, M. J. B. F. A definição terminológica do dicionário TERMISUL: expressão lingüística de relações conceptuais complexas. In: OLIVEIRA, A. M. P. P. D.; ISQUERDO, A. N. (Org.). As ciências do léxico. Lexicologia, lexicografia, terminologia. Campo Grande: Editora UFMS, 1998. p. 211-224.

HOUAISS, A. et al. Dicionário Houaiss da língua portuguesa. Versão monousuário 3.0. Instituto Antonio Houaiss. Rio de Janeiro: Editora Objetiva, 2009. 1 CD.

OXFORD ENGLISH DICTIONARY. [S.1.]: Oxford University Press, c2016. On-line. Disponível em: < https:/en.oxforddictionaries.com/definition/ online $>$. Acesso em: 9 abr. 2016.

PAVEL, S.; NOLET, D. Manual de terminologia. Adaptação para a língua portuguesa de Enilde Faulstich. Canada: Public Works and Government Services, 2002.

STREHLOW, R. A. Frames and the display of definitions. In: WRIGHT, S. E.; BUDIN, G. (Org.). Handbook of terminology management. Amsterdam, Philadelphia: John Benjamins Publishing Company, 1997. V. 1, p. 75-79.

VILARINHO, M. M. D. O. Proposta de dicionário informatizado analógico de língua portuguesa. 2013. 306 p. Tese (Doutorado em Linguística) - Instituto de Letras, Universidade de Brasília, Brasília, 2013.

WORDNIK ONLINE DICTIONARY. Millbrae, CA: Wordnik, [s.d.]. Disponível em: <https:/www.wordnik.com/>. Acesso em: 9 abr. 2016.

WÜSTER, E. La teoria general de la terminologia: una zona fronterera entre la lingüística, la lògica, l'ontologia, la informàtica i les ciènces especialitzades. In: CABRÉ, M. T. (Org.). Terminologia. Seleção de textos de E. Wüster. Barcelona: Servel de Llengua Catalana, Universitat de Barcelona, 1996. p. 153-204. 